\title{
Do we need biomarkers to predict the benefit of adding adjuvant taxanes for treatment of breast cancer?
}

\author{
José Pérez-García and Javier Cortés* \\ See related research by Jacquemier et al., http://breast-cancer-research.com/content/13/6/R109
}

\begin{abstract}
The current understanding of the molecular biology of breast cancer presents an extremely complex portrait of the disease. Based on this knowledge, considerable efforts are being made to identify biomarkers that will predict the response to a specific treatment while minimizing the risk of unnecessary side effects. In breast cancer, the Ki67 index has been associated with poor prognosis and might play a relevant role in predicting benefit from adjuvant docetaxel, as observed in the article accompanying this editorial. Taxanes are one of the most active cytotoxic agents for breast cancer. However, the role of taxane-based chemotherapy as adjuvant treatment of early breast cancer remains controversial in some subsets of patients. For this reason, the Ki67 index might help to better define the group of patients who could have the optimal benefit.
\end{abstract}

Gene expression profiling studies have classified breast tumors into a number of distinct intrinsic subtypes, and this has important implications for prognosis and therapy of the disease. The discovery of biomarkers that will predict responses to specific therapies is critical for advances in personalized medicine. Currently, however, there are few biomarkers employed in the clinic as predictive factors for treatment response in cases of breast cancer. In practice, only estrogen receptor (ER) and HER2 status are used. A third biomarker, the Ki67 labeling index, is a well-recognized cell proliferation marker that has been correlated with poor prognosis and

*Correspondence: jacortes@vhio.net

Breast Cancer Unit, Vall d'Hebron University Hospital, Universitat Autònoma de Barcelona, Passeig Vall d'Hebron 119-129, 08035 Barcelona, Spain higher chemosensitivity in breast cancer. However, assessment of the Ki67 index is still a matter of debate because of the lack of consensus in defining an optimal cutoff level.

In the previous issue of Breast Cancer Research, Jacquemier and colleagues [1] retrospectively assessed the prognostic and predictive value of subtyping breast cancer by immunohistochemistry and other multiple biomarkers in the PACS 01 trial. In this study, 1,999 patients with node-positive breast cancer were randomly assigned to receive six cycles of fluorouracil, epirubicin, and cyclophosphamide (FEC) or a sequential regimen of three cycles of FEC followed by three cycles of docetaxel [2]. The addition of docetaxel significantly improved the 5 -year rates of disease-free survival (DFS) $(73.2 \%$ versus $78.4 \% ; P=0.012)$ and overall survival $(86.7 \%$ versus $90.7 \% ; P=0.017)$.

In the article, the expression of 34 selected proteins, which included immunohistochemical determination of the Ki67 index and status of ER, progesterone receptor (PR), and HER2 as well as the evaluation of 30 additional proteins by tissue microarrays, was centrally analyzed in 1,099 tumor samples retrospectively. The authors concluded that high Ki67 index levels, defined as at least $20 \%$ of tumor cells displaying positive nuclear staining, were associated with shorter DFS but greater docetaxel benefit in patients with node-positive breast cancer treated with adjuvant anthracycline-based therapy. In addition, it was found that the luminal A subtype did not benefit from docetaxel treatment.

This study provides important insights into the biology and response to therapy of breast tumors. However, at least three considerations should be raised. First, although several studies have reported that higher Ki67 index levels predict better clinical and pathological response to neoadjuvant chemotherapy, the correlation between Ki67 index and the specific treatment benefit has not, to the best of our knowledge, been rigorously evaluated. Viale and colleagues [3] failed to demonstrate 
that Ki67 index levels predict which patients may benefit from adding a non-anthracycline adjuvant chemotherapy regimen to endocrine therapy. More recently, adjuvant assessment tools for the prediction of treatment benefit, including Oncotype Dx (Genomic Health, Redwood City, CA, USA) and MammaPrint (Agendia, Irvine, CA, USA), have been used to aid clinical decision making $[4,5]$. Oncotype Dx measures the expression of 21 genes, including proliferation-related genes such as MKi67, as major determinants in calculating an Oncotype Dx score [6]. With this molecular platform, both node-negative and node-positive patients with a high recurrence score showed a clear benefit from combined cyclophosphamide, methotrexate, and 5-fluorouracil (CMF) and anthracycline-based chemotherapy. Despite previously reported data to the contrary, the Ki67 index could play a relevant role in predicting benefit from adjuvant chemotherapy. Therefore, the Ki67 index seems to be a predictor of higher chemosensitivity in patients with breast cancer but is unable to predict the benefit of a specific treatment.

Second, although state-of-the-art intrinsic subtyping of breast tumors is based on molecular profiling of gene expression data from microarrays, these techniques are not ready for use in daily clinical practice. As a result, a combination of immunohistochemical surrogate markers, taking into account ER and PR status, HER2 status, histological grade, and Ki67 index, is being used for 'molecular subtyping. However, there is currently no consensus on how to establish a single immunohistochemical definition of each molecular subtype. 'Molecular subtyping' has been used to predict the benefit of adding adjuvant taxanes in patients with ER-positive breast cancer. A meta-analysis of 13 randomized trials evaluated the efficacy of including taxanes to anthracycline-based regimens. The addition of taxanes resulted in absolute 5 -year risk reductions of 5\% for DFS and 3\% for overall survival in patients with high-risk early breast cancer. This benefit was independent of ER expression and type of taxane [7]. However, unplanned retrospective analyses performed in each study have reported contradictory results. In relation to paclitaxel, the CALGB 9344 trial showed that, in comparison with patients with ERnegative or HER2-positive breast cancer, those with HER2-negative, ER-positive, and node-positive breast cancer obtained little benefit from the administration of paclitaxel after adjuvant doxorubicin-based therapy [8] However, other studies have not confirmed these results $[9,10]$. On the other hand, the efficacy of docetaxelcontaining adjuvant regimens was independent of ER expression in two randomized trials (PACS 01 and BCIRG 001) $[2,11]$. Therefore, the benefit of taxanes appears to be independent of ER expression.

Currently, it is well established that ER-positive breast cancers are highly heterogeneous. The luminal B subtype has a cell proliferation signature that includes expression of the MKi67 gene. Consequently, this subtype expresses high Ki67 index levels and has a significantly worse prognosis than luminal A tumors. Therefore, luminal B tumors may benefit from additional systemic therapy [12-14]. However, because luminal A tumors were observed to benefit from paclitaxel in the GEICAM 9906 study, it is unclear whether the benefit of taxanes is exclusively confined to patients with luminal B tumors. We cannot rule out the possibility that luminal A tumors benefit from adjuvant chemotherapy (a lack of benefit from taxanes is different than that from chemotherapy).

Third, the limitations of retrospective studies are well known. However, we must also be cautious when interpreting the results of subgroup analyses. Wang and colleagues [15] defined a subgroup analysis as 'any evaluation of treatment effects for a specific endpoint in subgroups of patients defined by baseline characteristics. This analysis is usually performed to evaluate the consistency of a trial's conclusions among patient subgroups included in the study [15]. A subgroup analysis can potentially support or alter our clinical decisions or do both. For this reason, we must take into account that inappropriate subgroup analysis can lead to invalid results. Consequently, an unplanned subgroup analysis should be considered exploratory and hypothesisgenerating only.

In conclusion, it is clear that the Ki67 index is a prognostic factor and a powerful predictor of higher chemosensitivity in patients with breast cancer. However, there are not enough data to establish a relationship between the Ki67 index and a therapy-specific benefit. As for the clinical implications of this study, 'molecular subtyping' and the Ki67 index will help to recommend the use, but not the type, of adjuvant chemotherapy.

\section{Abbreviations}

DFS, disease-free survival; ER, estrogen receptor; FEC, fluorouracil, epirubicin, and cyclophosphamide; PR, progesterone receptor.

\section{Competing interests}

The authors declare that they have no competing interests.

Published: 31 January 2012

\footnotetext{
References

1. Jacquemier J, Boher JM, Roche H, Esterni B, Serin D, Kerbrat $P$, Andre F, Finetti P, Charafe-Jauffret E, Martin AL, Campone M, Viens P, Birnbaum D, PenaultLlorca F, Bertucci F: Protein expression, survival and docetaxel benefit in node-positive breast cancer treated with adjuvant chemotherapy in the FNCLCC - PACS 01 randomized trial. Breast Cancer Res 2011, 13:R109.

2. Roché H, Fumoleau P, Spielmann M, Canon JL, Delozier T, Serin D, Symann M, Kerbrat P, Soulié P, Eichler F, Viens P, Monnier A, Vindevoghel A, Campone M,Goudier MJ, Bonneterre J, Ferrero JM, Martin AL, Genève J, Asselain B: Sequential adjuvant epirubicin-based and docetaxel chemotherapy for node-positive breast cancer patients: the FNCLCC PACS 01 Trial. J Clin Oncol 2006, 24:5664-5671.

3. Viale G, Regan MM, Mastropasqua MG, Maffini F, Maiorano E, Colleoni M, Price KN, Golouh R, Perin T, Brown RW, Kovács A, Pillay K, Ohlschlegel C, Gusterson BA, Castiglione-Gertsch M, Gelber RD, Goldhirsch A, Coates AS; International
} 
Breast Cancer Study Group: Predictive value of tumor Ki-67 expression in two randomized trials of adjuvant chemoendocrine therapy for nodenegative breast cancer. J Natl Cancer Inst 2008, 100:207-212.

4. Paik S, Tang G, Shak S, Kim C, Baker J, Kim W, Cronin M, Baehner FL, Watson D, Bryant J, Costantino JP, Geyer CE Jr, Wickerham DL, Wolmark N: Gene expression and benefit of chemotherapy in women with node-negative, estrogen receptor-positive breast cancer. J Clin Oncol 2006, 24:3726-3734.

5. van de Vijver MJ, He YD, van't Veer LJ, Dai H, Hart AA, Voskuil DW, Schreiber GJ, Peterse JL, Roberts C, Marton MJ, Parrish M, Atsma D, Witteveen A, Glas A,Delahaye L, van der Velde T, Bartelink H, Rodenhuis S, Rutgers ET, Friend SH, Bernards R: A gene-expression signature as a predictor of survival in breast cancer. N Engl J Med 2002, 347:1999-2009.

6. Sahebjam S, Aloyz R, Pilavdzic D, Brisson ML, Ferrario C, Bouganim N, Cohen V Miller WH J., Panasci LC: Ki 67 is a major, but not the sole determinant of Oncotype Dx recurrence score. Br J Cancer 2011, 105:1342-1345.

7. De Laurentiis M, Cancello G, D'Agostino D, Giuliano M, Giordano A, Montagna E, Lauria R, Forestieri V, Esposito A, Silvestro L, Pennacchio R, Criscitiello C,Montanino A, Limite G, Bianco AR, De Placido S: Taxane-based combinations as adjuvant chemotherapy of early breast cancer: a metaanalysis of randomized trials. J Clin Oncol 2008, 26:44-53.

8. Hayes DF, Thor AD, Dressler LG, Weaver D, Edgerton S, Cowan D, Broadwater G, Goldstein LJ, Martino S, Ingle JN, Henderson IC, Norton L, Winer EP, Hudis CA, Ellis MJ, Berry DA; Cancer and Leukemia Group B (CALGB) Investigators: HER2 and response to paclitaxel in node-positive breast cancer. NEng/J Med 2007, 357:1496-1506.

9. Sparano JA, Wang M, Martino S, Jones V, Perez EA, Saphner T, Wolff AC, Sledge GW Jr., Wood WC, Davidson NE: Weekly paclitaxel in the adjuvant treatment of breast cancer. N Engl J Med 2008, 358:1663-1671.

10. Martín M, Rodríguez-Lescure A, Ruiz A, Alba E, Calvo L, Ruiz-Borrego M, Munárriz B, Rodríguez CA, Crespo C, de Alava E, López García-Asenjo JA, Guitián MD, Almenar S, González-Palacios JF, Vera F, Palacios J, Ramos M, Gracia Marco JM, Lluch A, Alvarez I, Seguí MA, Mayordomo Jl, Antón A, Baena
JM, Plazaola A, Modolell A, Pelegrí A, Mel JR, Aranda E, Adrover E, et al: Randomized phase 3 trial of fluorouracil, epirubicin, and cyclophosphamide alone or followed by Paclitaxel for early breast cancer. J Natl Cancer Inst 2008, 100:805-814.

11. Martin M, Pienkowski T, Mackey J, Pawlicki M, Guastalla JP, Weaver C, Tomiak E, Al-Tweigeri T, Chap L, Juhos E, Guevin R, Howell A, Fornander T, Hainsworth J, Coleman R, Vinholes J, Modiano M, Pinter T, Tang SC, Colwell B, Prady C, Provencher L, Walde D, Rodriguez-Lescure A, Hugh J, Loret C, Rupin M, Blitz S,Jacobs P, Murawsky M, et al.: Adjuvant docetaxel for node-positive breast cancer. NEngl J Med 2005, 352:2302-2313.

12. Hugh J, Hanson J, Cheang MC, Nielsen TO, Perou CM, Dumontet C, Reed J, Krajewska M, Treilleux I, Rupin M, Magherini E, Mackey J, Martin M, Vogel C: Breast cancer subtypes and response to docetaxel in node-positive breast cancer: use of an immunohistochemical definition in the BCIRG 001 trial. J Clin Oncol 2009, 27:1 168-1176.

13. Cheang MC, Chia SK, Voduc D, Gao D, Leung S, Snider J, Watson M, Davies S, Bernard PS, Parker JS, Perou CM, Ellis MJ, Nielsen TO: Ki67 index, HER2 status, and prognosis of patients with luminal B breast cancer. J Natl Cancer Inst 2009, 101:736-750.

14. Penault-Llorca F, André F, Sagan C, Lacroix-Triki M, Denoux Y, Verriele V, Jacquemier J, Baranzelli MC, Bibeau F, Antoine M, Lagarde N, Martin AL, Asselain B, Roché H: Ki67 expression and docetaxel efficacy in patients with estrogen receptor-positive breast cancer. J Clin Oncol 2009, 27:2809-2815.

15. Wang R, Lagakos SW, Ware JH, Hunter DJ, Drazen JM: Statistics in medicine reporting of subgroup analyses in clinical trials. N Engl J Med 2007, 357:2189-2194.

doi:10.1186/bcr3093

Cite this article as: Pérez-García J, Cortés J: Do we need biomarkers to predict the benefit of adding adjuvant taxanes for treatment of breast cancer? Breast Cancer Research 2012, 14:104. 